\title{
Keynesian Economics Without the LM and IS Curves: A Dynamic Generalization of the Taylor- ROMer Model
}

\author{
Evan F. KoENIG \\ Research Department \\ Working Paper 0813
}

Federal Reserve Bank of Dallas 
Keynesian Economics without the LM and IS Curves:

A Dynamic Generalization of the Taylor-Romer Model

\author{
by \\ Evan F. Koenig \\ Adjunct Professor of Economics \\ Southern Methodist University \\ Vice President and Senior Policy Advisor \\ Federal Reserve Bank of Dallas \\ 2200 N. Pearl Street \\ Dallas, TX 75201 \\ evan.f.koenig@dal.frb.org
}

September 2008 


\title{
Keynesian Economics without the LM and IS Curves: A Dynamic Generalization of the Taylor-Romer Model
}

\begin{abstract}
John Taylor and David Romer champion an approach to teaching undergraduate macroeconomics that dispenses with the LM half of the IS-LM model and replaces it with a rule for setting the interest rate as a function of inflation and the output gap-i.e., a Taylor rule. But the IS curve is problematic, too. It is consistent with the permanent-income hypothesis only when the interest rate that enters the IS equation is a long-term rate-not the short-term rate controlled by the monetary authority. This article shows how the Taylor-Romer framework can be readily modified to eliminate this maturity mis-match. The modified model is a dynamic system in output and inflation, with a unique stable path that behaves very much like Taylor and Romer's aggregate demand $(\mathrm{AD})$ schedule. Many-but not all-of the original Taylor-Romer model's predictions carry over to the new framework. It helps bridge the gap between the Taylor-Romer analysis and the more sophisticated models taught in graduate-level courses.
\end{abstract}


Koenig (1987, 1990, 1993a,b), Kerr and King (1996), and McCallum and Nelson (1999) propose that the intertemporal maximization condition, or Euler equation, of the representative household be used in place of the IS curve in IS-LM analysis. This paper makes a similar substitution within the macroeconomic framework championed by Taylor (2000) and Romer (2000) as an alternative to the textbook IS-LM model. ${ }^{1}$ The Taylor-Romer framework keeps the traditional IS and Phillips curves, but dispenses with the LM curve, replacing it with a rule for setting the short-term real interest rate as a function of inflation and the output gap [Taylor (1993); Henderson and McKibbin (1993)]. There is nothing wrong with the LM curve, in principle. However, neither policymakers nor the financial and popular press discuss monetary policy, these days, except in terms of whether the short-term interest rate is appropriate, given the state of the economy. Consequently, it is difficult to motivate the study of a model which assumes that the central bank targets the money supply. ${ }^{2}$

What's wrong with the traditional IS curve? The IS equation used by Taylor, Romer, and most textbooks posits that aggregate demand is decreasing in "the" real interest rate. While its term is left vague, the fact that the IS curve is combined with an LM curve (in textbook treatments of the IS-LM model) or with a Taylor rule (in the Taylor-Romer model), means that the interest rate in the IS equation can only be a short-term rate. This implicit assumption is difficult to reconcile with modern treatments of the permanent income hypothesis. After all, standard microeconomic theory says that each household seeks to equate the marginal rate of substitution between current and future consumption to one plus the real interest rate. Assuming a constant elasticity of substitution between consumption today and consumption tomorrow, $\sigma$, and a constant pure rate of time preference, $\rho$, this optimality condition implies that 


$$
\left(E_{t} y_{t+T}-y_{t}\right) / T=\sigma\left(r_{t}^{T}-\rho\right)
$$

whenever the household is not credit constrained. Here $E_{t}(\cdot)$ is the mathematical expectation based on period- $t$ information, $y_{t}$ is (the logarithm of) current consumption, $y_{t+T}$ is (log) consumption $T$ periods ahead, and $r_{t}^{T}$ is the current $T$-period real interest rate. ${ }^{3}$ The presence of the expectation operator makes it clear that Equation 1 is an optimal planning condition. If new information arrives, the planned consumption path may change.

A special case of Equation 1 is $T=T^{*}$, where $T^{*}$ is the number of periods it takes for the economy to achieve market-clearing equilibrium following a nominal shock, in the absence of additional disturbances. Then, Equation 1 can be rearranged to obtain:

$$
y_{t}=E_{t} y_{t+T^{*}}^{*}-\sigma T^{*}\left(r^{T^{*}}-\rho\right),
$$

where $y_{t+T^{*}}^{*}$ is market-clearing household consumption $T^{*}$ periods from now. If $y_{t+T^{*}}^{*}$ is independent of monetary policy (if money is neutral in the long run), then Equation 2 looks like a textbook IS curve: It gives a trade-off between current demand and the real interest rate that is unaffected by monetary policy. ${ }^{4,5,6}$ Unless nominal frictions are expected to dissipate after only one period, however, (in which case they are hardly worth worrying about) the interest rate that matters in Equation 2 is a long-term rate, not the short rate that is under the control of the monetary authority and which, when added to current inflation, determines the opportunity cost of holding high-powered money. ${ }^{7}$

To eliminate the maturity mis-match implicit in textbook treatments, Koenig $(1987,1990$, 
1993a,b), McCallum and Nelson (1999), and Kerr and King (1996) proposed working with the version of Equation 1 in which $T$ equals 1 rather than $T^{*}$. The effect is to replace a relationship between the level of output and the real interest rate with a relationship between expected output growth and the real interest rate, adding a new, dynamic element to IS-LM analysis. When a similar substitution is made in the Taylor-Romer framework, it adds a dynamic output-adjustment equation to the inflation-adjustment equation already in the model.

The additional complexity resulting from the substitution is surprisingly small. The modified Taylor-Romer model can be analyzed graphically in output-inflation space using a simple phase diagram. The economy has a unique stable path that looks and behaves much like Taylor and Romer's aggregate demand (AD) schedule. Advanced undergraduates and new graduate students have no trouble manipulating this diagram and tracing the economy's adjustment. For some shocks, it's actually easier to see how the economy's steady state changes using the phase diagram than it is using the original Taylor-Romer AD equation.

In broad terms, the modified framework provides a bridge between the Taylor-Romer analysis and the forward-looking, rational expectations models taught in graduate-level courses. It reassures students who are familiar with the Taylor-Romer framework that many of its predictions remain valid in a world where households behave in a manner consistent with microeconomic theory, and alerts them to circumstances under which the Taylor-Romer predictions are likely to break down. 


\section{THE TAYLOR-ROMER FRAMEWORK}

The Taylor-Romer model consists of three equations: (1) a traditional IS relationship between output, $y$, and the real interest rate, $r$; (2) a Taylor or "monetary policy" interest-rate rule that gives the real interest rate as a function of the gap, $y-y^{*}$, between output and its marketclearing level and the gap, $\pi-\pi^{*}$, between actual and target inflation; and (3) a Phillips curve that says inflation will rise faster, the greater is the output gap. Formally,

$$
\begin{array}{ll}
\text { IS: } \quad & y=y^{*}-\sigma(r-\rho) \\
\text { MP: } & r=\rho+\tau_{y}\left(y-y^{*}\right)+\tau_{\pi}\left(\pi-\pi^{*}\right) \\
\text { PC: } \quad & i=\varphi\left(y-y^{*}\right),
\end{array}
$$

where $\rho, \sigma, \tau_{\pi}$, and $\varphi$ are positive parameters and $\tau_{y}$ is a non-negative parameter. It's important to note that the accelerationist Phillips curve implies that inflation can never "jump." Its time-path is continuous ( $\dot{\pi}$ is finite). No such restriction applies to output.

The monetary-policy equation can be used to eliminate the interest rate from the IS equation, yielding a negative "aggregate demand" relationship between output and inflation: ${ }^{8}$

$$
\mathrm{AD}: \quad y=y^{*}-\frac{\sigma \tau_{\pi}}{1+\sigma \tau_{y}}\left(\pi-\pi^{*}\right) .
$$

In $y \times \pi$ space, Equation 6 defines a downward-sloping $\mathrm{AD}$ schedule that passes through the point $\left(y^{*}, \pi^{*}\right)$. The economy must be on this schedule at all times. Meanwhile, Equation 5 divides $y \times \pi$ 
space in half: When $y>y^{*}$, inflation is rising; and when $y<y^{*}$, inflation is falling. It follows that the economy moves up along the $\mathrm{AD}$ schedule toward $\left(y^{*}, \pi^{*}\right)$ whenever $y>y^{*}$, and moves down along the $\mathrm{AD}$ schedule toward $\left(y^{*}, \pi^{*}\right)$ whenever $y<y^{*} .{ }^{9,10}$ See Figure 1.

\section{Examples}

A New Fed Chairman. Suppose that the economy is in steady state, at $\left(y^{*}, \pi^{*}\right)$, when a Federal Reserve chairman who wants to lower inflation to $\pi^{* \prime}<\pi^{*}$ is confirmed. In Equation $4, \pi^{* \prime}$ suddenly replaces $\pi^{*}$. It follows that the AD schedule will shift downward to pass through $\left(y^{*}, \pi^{* \prime}\right)$. Since inflation cannot jump (c.f. Equation 5), it is output that adjusts to put the economy on the new $\mathrm{AD}$ schedule. Specifically, output instantly drops from $y^{*}$ to $y_{A} \equiv y^{*}-$ $\left[\sigma \tau_{\pi^{\prime}} /\left(1+\sigma \tau_{y}\right)\right]\left(\pi^{*}-\pi^{* \prime}\right)$. In Figure 2 , the economy jumps from $\left(y^{*}, \pi^{*}\right)$ to $\left(y_{A}, \pi^{*}\right)$. With output now below potential, inflation gradually declines and, as it does so, the economy moves down the AD schedule toward $\left(y^{*}, \pi^{* \prime}\right)$. The Fed's more hawkish inflation stance triggers a recession.

A Fall in Potential Output. Alternatively, suppose that the economy is in steady state, at $\left(y^{*}, \pi^{*}\right)$, when potential output suddenly drops to $y^{*^{\prime}}<y^{*}$. To make the example more interesting, assume that the central bank is unaware of the change in potential output and continues to follow the same policy rule as before. Orphanides (2002) argues that something of the sort happened in the United States during the 1970s. Solving the new IS equation (with $y^{* \prime}$ in place of $y^{*}$ ) and the unchanged MP equation (with $y^{*}$, as before) the post-shock AD equation takes the form:

$$
\mathrm{AD}^{\prime}: \quad y=\frac{1}{1+\sigma \tau_{y}} y^{* t}+\frac{\sigma \tau_{y}}{1+\sigma \tau_{y}} y^{*}-\frac{\sigma \tau_{\pi}}{1+\sigma \tau_{y}}\left(\pi-\pi^{*}\right) .
$$


The implication is that the AD schedule shifts, horizontally, by less than the full drop in potential output. Intuitively, because the Fed fails to recognize the decline in potential output, it resists declines in actual output by cutting the interest rate. In the short term, then, output falls from $y^{*}$ to $y_{A} \equiv\left[1 /\left(1+\sigma \tau_{y}\right)\right] y^{* \prime}+\left[\sigma \tau_{y} /\left(1+\sigma \tau_{y}\right)\right] y^{*}$ rather than to $y^{* \prime}$. Because $y_{A}>y^{* \prime}$, there is upward pressure on the inflation rate, and the economy gradually moves up the new AD schedule. Following this bout of "stagflation"-declining output accompanied by rising inflation-the economy eventually ends up with output equal to $y^{* \prime}$ and inflation equal to $\pi^{*}+\left(\tau_{y} / \tau_{\pi}\right)\left(y^{*}-y^{* \prime}\right)>$ $\pi^{*}$ (Figure 3).

Paradoxically, the only way, in Figure 3, for the Fed to eliminate deviations of output from potential is to ignore the output gap when setting policy. Formally, note that if the weight, $\tau_{y}$, placed on the output gap in the Taylor rule is set equal to zero, then the post-shock aggregate demand schedule, Equation 7, reduces to: $y=y^{* 1}-\sigma \tau\left(\pi-\pi^{*}\right)$. The AD schedule now shifts, horizontally, by the full amount of the drop in potential output. The economy moves directly from its old steady-state equilibrium, $\left(y^{*}, \pi^{*}\right)$, to a new steady-state equilibrium at $\left(y^{* \prime}, \pi^{*}\right)$. The output gap stays at zero and inflation remains constant at its target value.

\section{A DYNAMIC GENERALIZATION OF TAYLOR-ROMER}

As noted above, Equation 3-the Taylor-Romer IS schedule-is inconsistent with household intertemporal utility maximization if $r$ is a short-term interest rate. An alternative specification, which is consistent with the maximization conditions that students are taught in their intermediate micro classes, comes from the special case of Equation 1 where $T=1$. In continuous time, Equation 3 is replaced by 
IS: $\quad \dot{y}=\sigma(r-\rho)$.

It is understood that Equation 3' may only be violated when new information arrives that is pertinent to households' planned spending paths. Output may “jump” coincident with the arrival of such information.

The monetary-policy and Phillips curve specifications, Equations 4 and 5, are unaltered. ${ }^{11}$

$$
\begin{array}{ll}
\text { MP: } & r=\rho+\tau_{y}\left(y-y^{*}\right)+\tau_{\pi}\left(\pi-\pi^{*}\right) \\
\text { PC: } \quad & i=\varphi\left(y-y^{*}\right) .
\end{array}
$$

From Equation 5, inflation rises when $y>y^{*}$ and falls when $y<y^{*}$, exactly as before. Meanwhile, Equations 3' and 4 determine the dynamics of output:

$$
\dot{y}=\sigma\left[\tau_{y}\left(y-y^{*}\right)+\tau_{\pi}\left(\pi-\pi^{*}\right)\right]
$$

According to Equation 8, output rises when $\pi>\pi^{*}-\left(\tau_{y} / \tau_{\pi}\right)\left(y-y^{*}\right)$ and falls when $\pi<\pi^{*}$ $\left(\tau_{y} / \tau_{\pi}\right)\left(y-y^{*}\right)$. In the former case, inflation is so high that the Fed sets the interest rate above the rate of time preference. Households defer their spending, putting output on a rising path. In the latter case, inflation is low enough that the Fed sets the interest rate below the rate of time preference, encouraging households to push their spending forward: Output falls through time. The $y \times \pi$ plane is now divided into four regions. A vertical line, labeled $\dot{\pi}=0$ in Figure 4, 
separates regions where inflation is falling from those where inflation is rising. A downward sloping line, labeled $\dot{y}=0$, divides regions where output is rising from regions where output is falling. The point $\left(y^{*}, \pi^{*}\right)$ itself is a saddle-point equilibrium: There is a unique, downwardsloping, "knife's-edge" path (labeled "KE" in Figure 4) that takes the economy toward $\left(y^{*}, \pi^{*}\right) .{ }^{12}$

\section{Examples}

A New Fed Chairman. Suppose that the economy is initially in steady state at $\left(y^{*}, \pi^{*}\right)$. If a new, lower inflation target $\left(\pi^{* \prime}<\pi^{*}\right)$ is adopted, nothing happens to the $\dot{\pi}=0$ schedule in the phase diagram-its position is completely determined by $y^{*}-$ but the $\dot{y}=0$ schedule will shift downward and, along with it, the knife's-edge path that leads to the economy's new steady state. The economy must be on this path when the new monetary policy is implemented. How it gets there depends on whether the new policy is a surprise or announced in advance.

If a surprise, then the economy behaves very much as it does in the Taylor-Romer model, with the knife's edge playing the role of the $\mathrm{AD}$ schedule. Households react to the announcement of the new policy by re-evaluating their spending plans, cutting back on current consumption by enough to move the economy directly to the new knife's-edge path (point A in Figure 5). Then, the economy moves gradually down the knife's edge to $\left(y^{*}, \pi^{* \prime}\right)$, just as it moves down the AD schedule in the Taylor-Romer model.

If the new inflation target is announced in advance, households have a chance to adjust their spending plans early, to smooth out their consumption paths. The early adjustment will be just large enough so that if inflation and spending subsequently evolve according to Equations 5 
and 8 , the economy will reach the new knife's edge at the same instant that the new policy rule is implemented. In Figure 5, the economy jumps from $\left(y^{*}, \pi^{*}\right)$ to a point like B when the announcement arrives, then follows the arrows pointing to the southwest, reaching point $\mathrm{C}$ on the new knife's edge just as the lower inflation target becomes effective. From point $\mathrm{C}$, the economy moves gradually down the knife's edge to $\left(y^{*}, \pi^{* \prime}\right)$. Lowering the inflation target still triggers a recession, but a recession that is neither as sharp nor as deep as before.

Critically, Equation 3' introduces a forward-looking element into the economy's response to shocks-a forward-looking element that is inherent in the permanent-income hypothesis and missing from the Taylor-Romer model. To the extent that they are known about in advance, the economy responds in anticipation of shocks. In doing so, it moves-temporarily-away from that knife's-edge path that serves as the new model's version of the $\mathrm{AD}$ schedule. ${ }^{13} \mathrm{AD}$ departures are never observed in the Taylor-Romer model.

A Fall in Potential Output. Shifts in potential output are easy to analyze in the phase-diagram framework. As before, consider a 1970s-style sudden fall in potential output, to $y^{*^{\prime}}<y^{*}$, which the central bank fails to recognize has occurred. Because the monetary-policy rule is unchanged, so is Equation 8, and so is the position of the $\dot{y}=0$ schedule. On the other hand, the fall in potential output causes the vertical $\dot{\pi}=0$ schedule to shift left. Since the knife's-edge path must pass through the intersection of the $\dot{y}=0$ and $\dot{\pi}=0$ schedules, it too shifts left. Household spending drops immediately by enough to put the economy on the new knife's-edge path, which is by less than the full decline in potential output. (In Figure 6, output jumps to $y_{A}$.) Subsequently, 
the economy moves gradually to the northwest, along the knife's edge, until $y=y^{* \prime}$ and $\pi=\pi^{*}+$ $\left(\tau_{y} / \tau_{\pi}\right)\left(y^{*}-y^{* \prime}\right)$

The nice thing about the phase-diagram apparatus is that it is immediately clear, without any algebraic manipulations, how the $\dot{y}=0$ and $\dot{\pi}=0$ schedules respond to a change in potential output, and hence how the knife's-edge path (the surrogate AD schedule) must shift.

The paradox cited earlier continues to hold: When there are imperfectly observed shifts in potential output, the only way for the monetary authority to eliminate deviations of output from potential is to completely ignore the output gap when setting policy. In Figure 6, the effect of setting $\tau_{y}=0$ in the policy function is to make the $\dot{y}=0$ schedule horizontal. The knife's-edge path now shifts leftward by the full decline in potential output, and the economy moves directly from $\left(y^{*}, \pi^{*}\right)$ to $\left(y^{* 1}, \pi^{*}\right)$.

\section{An Illusory IS Curve}

We have seen that there is a negative and monetary-policy-independent relationship between current spending and the long-term real interest rate (c.f. Equation 2). There is also a negative and monetary-policy-independent relationship between planned spending growth and the short-term real interest rate (c.f. Equation $\left.3^{\prime}\right)$. Here, we point out that, much of the time, the data will give the illusion of an IS-style, negative relationship between the short-term real rate and the level of current spending. This pseudo-IS relationship arises because there is a close connection between the level of spending and the growth rate of spending whenever the economy is on the knife's-edge path. However, when the economy is off the knife's edge-i.e., when households 
learn in advance of a shift in the economic environment-the inverse empirical relationship between the short-term real interest rate and level of spending will break down. Moreover, the pseudo-IS relationship is not independent of monetary policy.

Formally, along the knife's-edge path,

$$
\pi-\pi^{*}=\left(\varphi / \lambda_{1}\right)\left(y-y^{*}\right),
$$

where

$$
\lambda_{1}=\frac{1}{2}\left[\sigma \tau_{y}-\sqrt{\sigma^{2} \tau_{y}^{2}+4 \varphi \sigma \tau_{\pi}}\right]<0
$$

is the stable root of the differential equation system consisting of Equations 5 and 8. Substituting back into Equation 8,

$$
\dot{y}=\sigma\left(\tau_{y}+\tau_{\pi} \varphi / \lambda_{1}\right)\left(y-y^{*}\right),
$$

along the knife's-edge path. Finally, combine Equations 3' and 11:

$$
y-y^{*}=(r-\rho) /\left(\tau_{y}+\tau_{\pi} \varphi / \lambda_{1}\right) .
$$

It is readily verified that $\left(\tau_{y}+\tau_{\pi} \varphi / \lambda_{1}\right)<0$, so that the output gap is negatively related to the real short-term interest rate provided the economy is traveling along the knife's edge toward its steady 
state.

Although Equation 3" has the same form as a traditional IS equation (c.f. Equation 3), it is subject to the Lucas critique: Output's sensitivity to interest-rate changes depends on the coefficients of the monetary-policy reaction function, $\tau_{y}$ and $\tau_{\pi^{*}}$

\section{SUMMARY AND CONCLUSIONS}

The analysis presented here reinforces the case for using the Taylor-Romer model as the basic framework for teaching macroeconomics at the principles level. Although the TaylorRomer model blurs the distinction between the short-term interest rate that is controlled by the monetary authority and the long-term rate that theory suggests matters most for household spending, this shortcoming turns out to be unimportant for tracing the economic effects of surprise shifts in exogenous variables. Moreover, the maturity mismatch is easily remedied by replacing the Taylor-Romer IS equation with a household Euler equation, and the Taylor-Romer AD diagram with a simple phase diagram.

The modified Taylor-Romer model can be used to illustrate how under the permanent income hypothesis the economy responds in anticipation of policy and other exogenous shifts, to the extent the shifts become known in advance. The model also nicely illustrates the Lucas critique: Output and real-interest-rate data may appear to obey a traditional IS relationship, but with optimizing households this relationship is not reliable and its slope is not independent of the conduct of monetary policy. In general, the model provides a useful transition between the principles-level Taylor-Romer analysis and the more sophisticated macro models taught in graduate-level courses. 


\section{NOTES}

1. See, also, Turner (2006).

2. "False to reality, unconnected with the flow of news, needlessly complex, and leading to problems in discussing the dynamic evolution of the economy-these four reasons to downplay the LM curve are not balanced by any offsetting advantages." - Bradford DeLong (undated)

3. Equation 1 ignores a risk premium, assumes that the real interest rate is known (sensible now that the Treasury issues inflation-protected securities), and makes use of the approximation $\ln (1+x) \approx x$ for small $x$.

4. Taylor (2000) lists the long-run neutrality of money with respect to real variables as one of "five key components of modern macroeconomics."

5. Consistent with the permanent-income hypothesis, current consumption depends on long-run prospects, captured by $E_{t} y_{t+T^{*}}$, but is also affected by the real interest rate. The higher the real interest rate, the more willing are households to defer consumption-i.e., the steeper is the planned consumption path.

6. Equation 2 can easily be put into output-gap form:

$$
y_{t}-y_{t}^{*}=E_{t}\left(y_{t+T^{*}}^{*}-y_{t}^{*}\right)-\sigma T^{*}\left(r^{T^{*}}{ }_{t}-\rho\right)
$$

Only shocks that affect expected growth in market-clearing output shift this version of the IS schedule.

7. For an even harsher assessment of the traditional IS curve-and the IS-LM model as a whole-see King (1993).

8. Romer (2000) shows how to do this using graphs of the IS and MP equations in $y \times r$ space. 
9. Key to this convergent behavior is the assumption that $\tau_{\pi}$ is greater than zero. If this condition-the "Taylor principle"-is violated, then the AD schedule is upward rather than downward sloping, and the economy tends to move away from $\left(y^{*}, \pi^{*}\right)$, with inflation and output either both exploding or both imploding.

10. Clearly, the entire analysis could be conducted in terms of the output gap and inflation, rather than output and inflation. The gap formulation has the advantage that it allows for potential output to have a trend. Its disadvantage is that it somewhat obscures the implications for output of a shock to potential output.

11. For simplicity, the analysis in the main text assumes that potential output is expected to remain constant. Relaxing this assumption requires that the monetary-policy rule be altered, slightly, to reflect the fact that the flex-price equilibrium real interest rate is increasing in the economy's growth rate. In particular, one needs to replace Equation 4 with: $r=\rho+(1 / \sigma) \dot{y}^{*}+$ $\tau_{y}\left(y-y^{*}\right)+\tau_{\pi}\left(\pi-\pi^{*}\right)$. The phase-diagram analysis in the main text carries through, much as before, but in $\left(y-y^{*}\right) \times \pi$ space instead of $y \times \pi$ space.

12. Formally, Equations 5 and 8 form a system of linear differential equations. The roots of this system are $\lambda_{1}=(1 / 2)\left\{\sigma \tau_{y}-\left[\left(\sigma \tau_{y}\right)^{2}+4 \varphi \sigma \tau_{\pi}\right]^{1 / 2}\right\}$ and $\lambda_{2}=(1 / 2)\left\{\sigma \tau_{y}+\left[\left(\sigma \tau_{y}\right)^{2}+4 \varphi \sigma \tau_{\pi}\right]^{1 / 2}\right\}$. Provided that $\tau_{\pi}>0$ (the Taylor principle), the first root is negative and the second is positive. The stable path, or knife's edge, through $\left(y^{*}, \pi^{*}\right)$ has the equation $\pi=\pi^{*}+\left(\varphi / \lambda_{1}\right)\left(y-y^{*}\right)$. Recalling that $\lambda_{1}$ $<0$, the stable path is downward sloping. Transversality conditions imply that it is optimal.

13. Suppose that a one-time change in policy (or some other exogenous variable) is announced at $t=0$, to take effect at $t=S \geq 0$. The response of the economy must obey the following principles: (1) At $t=0$, households re-evaluate their spending plans in light of the announced change. Output may jump. (2) For $0<t \leq S$, the pre-shock Euler conditions continue to apply. The economy is governed by the original phase diagram. (3) At $t=S$, the economy must be on the post-shock knife's-edge path. The $t=0$ output jump is determined by the requirement that this be so. (4) For $t>S$, the post-shock dynamics apply, and the economy follows the new knife's-edge path toward steady state. 


\section{References}

DeLong, Bradford (undated), www.j-bradford-delong.net/macro_online/interest_rates_ms.html.

Henderson, Dale W. and Warwick J. McKibbin (1993) "A Comparison of Some Basic Monetary Policy Regimes for Open Economies: Implications of Different degrees of Instrument Adjustment and Wage Persistence," Carnegie-Rochester Conference Series on Public Policy 39, (December), 221-317.

Kerr, William and Robert G. King (1996) "Limits on Interest Rate Rules in the IS Model," Federal Reserve Bank of Richmond Economic Quarterly 82, (2), 47-75.

King, Robert G. (1993) "Will the New Keynesian Macroeconomics Resurrect the IS-LM Model?" Journal of Economic Perspectives 7, (1), 67-82.

Koenig, Evan F. (1987) "A Dynamic Optimizing Alternative to Traditional IS-LM Analysis," University of Washington Institute for Economic Research Discussion Paper \#87-07.

(1990) "Is Increased Price Flexibility Stabilizing? The Role of the Permanent Income Hypothesis," Federal Reserve Bank of Dallas Research Paper No. 9011.

(1993a) "Rethinking the IS in IS-LM: Adapting Keynesian Tools to Non-Keynesian Economies, Part 1" Federal Reserve Bank of Dallas Economic Review, Q3, 33-49.

(1993b) "Rethinking the IS in IS-LM: Adapting Keynesian Tools to Non-Keynesian Economies, Part 2" Federal Reserve Bank of Dallas Economic Review, Q4, 17-35. 
McCallum, Bennett T. and Edward Nelson (1999) “An Optimizing IS-LM Specification for Monetary Policy and Business Cycle Analysis,” Journal of Money, Credit, and Banking 31 (August, Part 1), 296-316.

Orphanides, Athanasios (2002) "Monetary-Policy Rules and the Great Inflation," American Economic Review 92, (2), 115-120.

Romer, David (2000) “Keynesian Macroeconomics without the LM Curve," Journal of Economic Perspectives 14, (2), 149-169.

Taylor, John B. (1993) “Discretion versus Policy Rules in Practice,” Carnegie-Rochester Conference Series on Public Policy 39, (December), 195-214.

(2000) "Teaching Modern Macroeconomics at the Principles Level," American Economic Review 90, (2), 90-94.

Turner, Paul (2006) "Teaching Undergraduate Macroeconomics with the Taylor-Romer Model," International Review of Economic Education 5, (1), 73-82. 


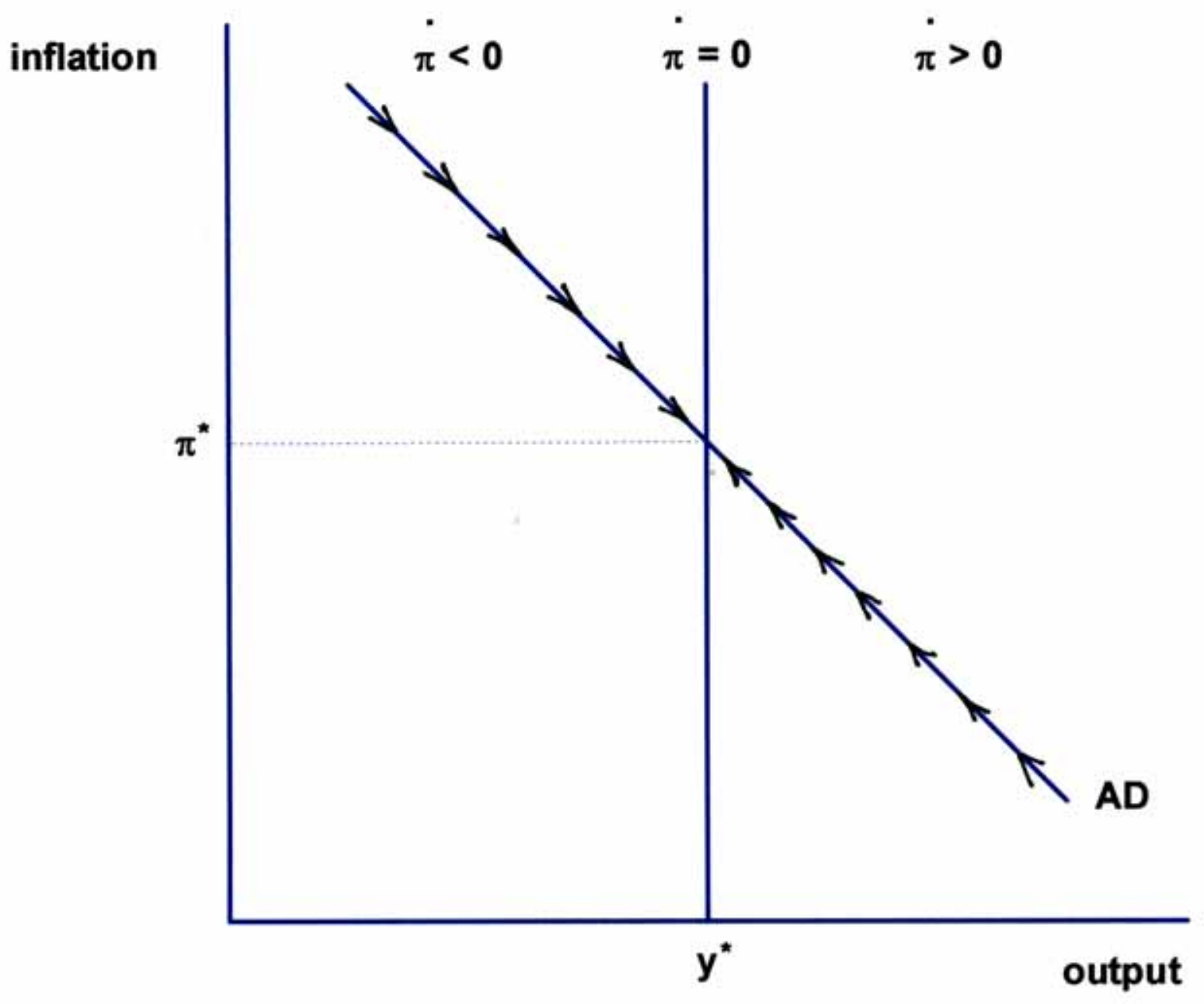

FIGURE 1. The economy moves along the AD schedule toward $\left(y^{*}, \pi^{*}\right)$. 


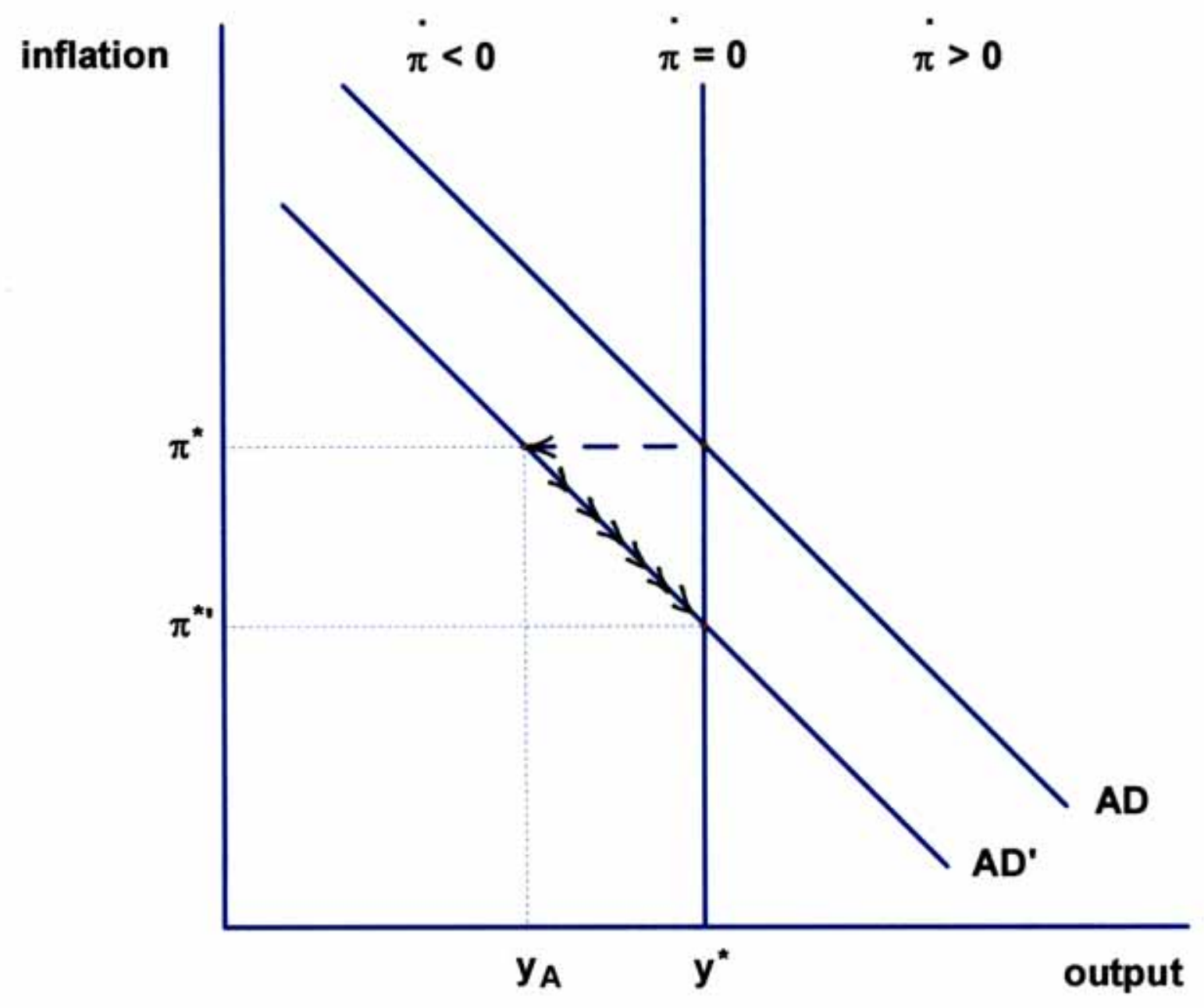

FIGURE 2. A reduction in the Fed's inflation target triggers a recession. 


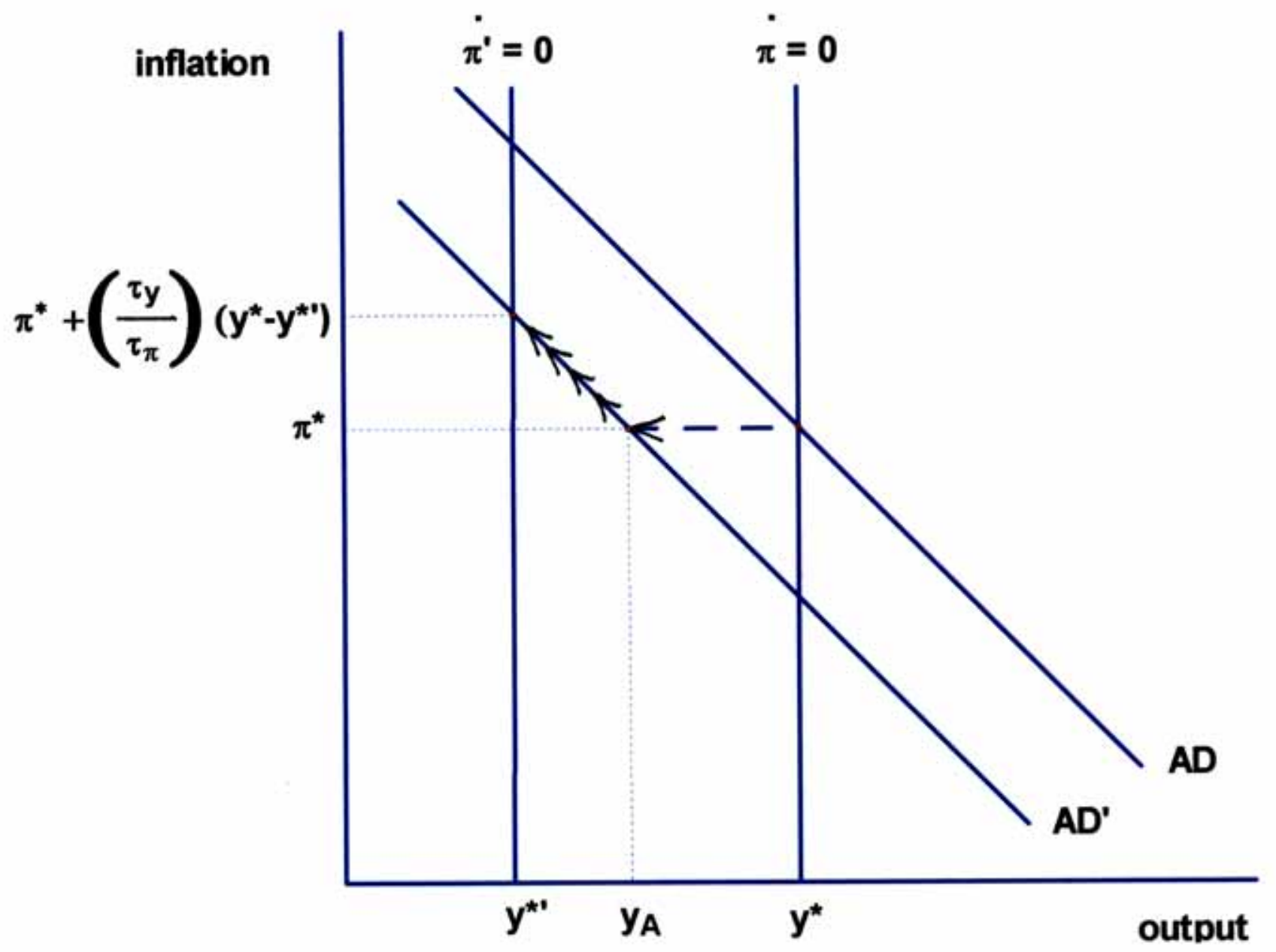

FIGURE 3. An unrecognized fall in potential output leads to stagflation. 


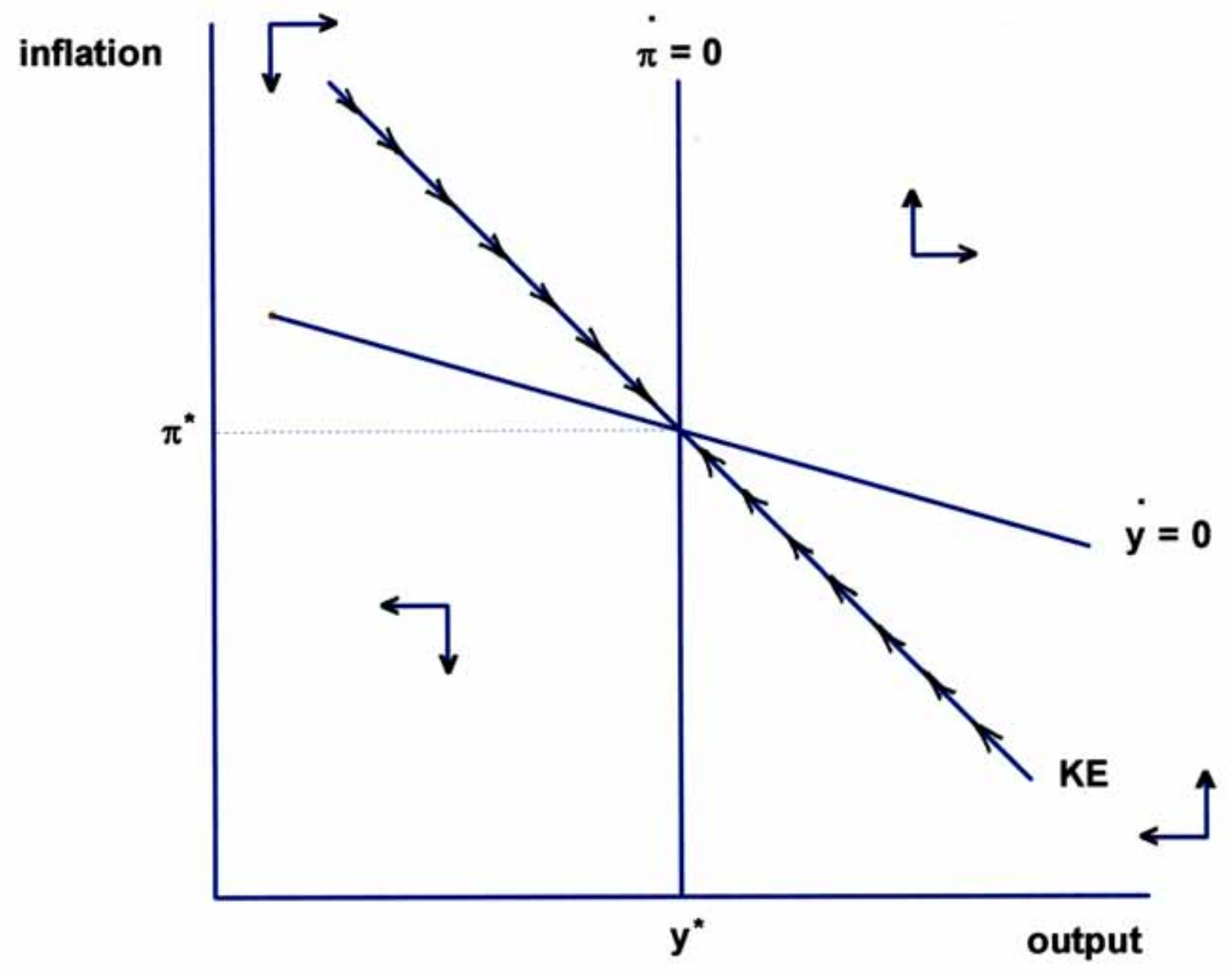

FIGURE 4. Under the permanent income hypothesis, the economy has a unique "knife's-edge" path that converges to $\left(y^{*}, \pi^{*}\right)$. 


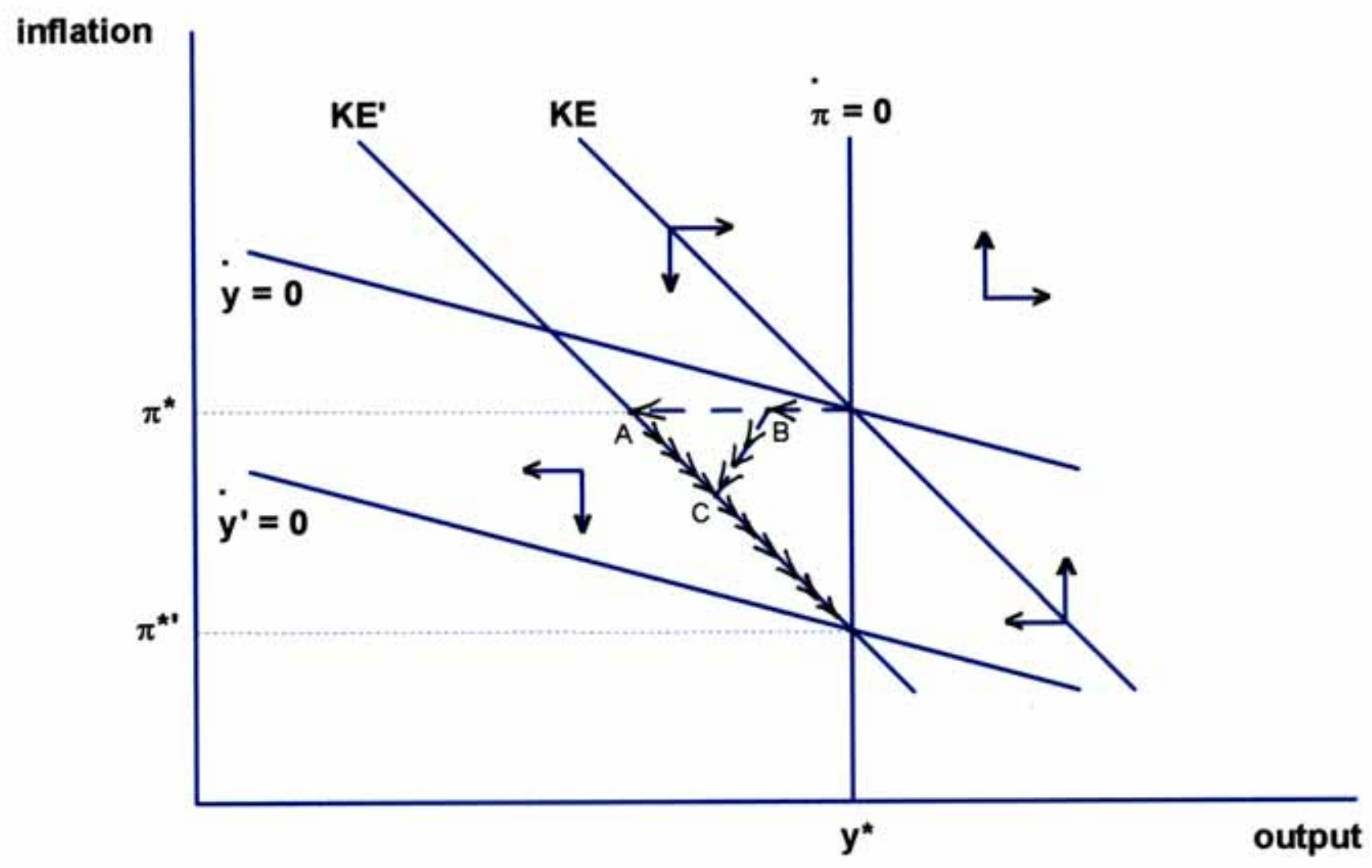

FIGURE 5. Without advance warning, a reduction in the Fed's inflation target triggers a jump to point $A$. With advance warning, the economy jumps only to point $B$. 


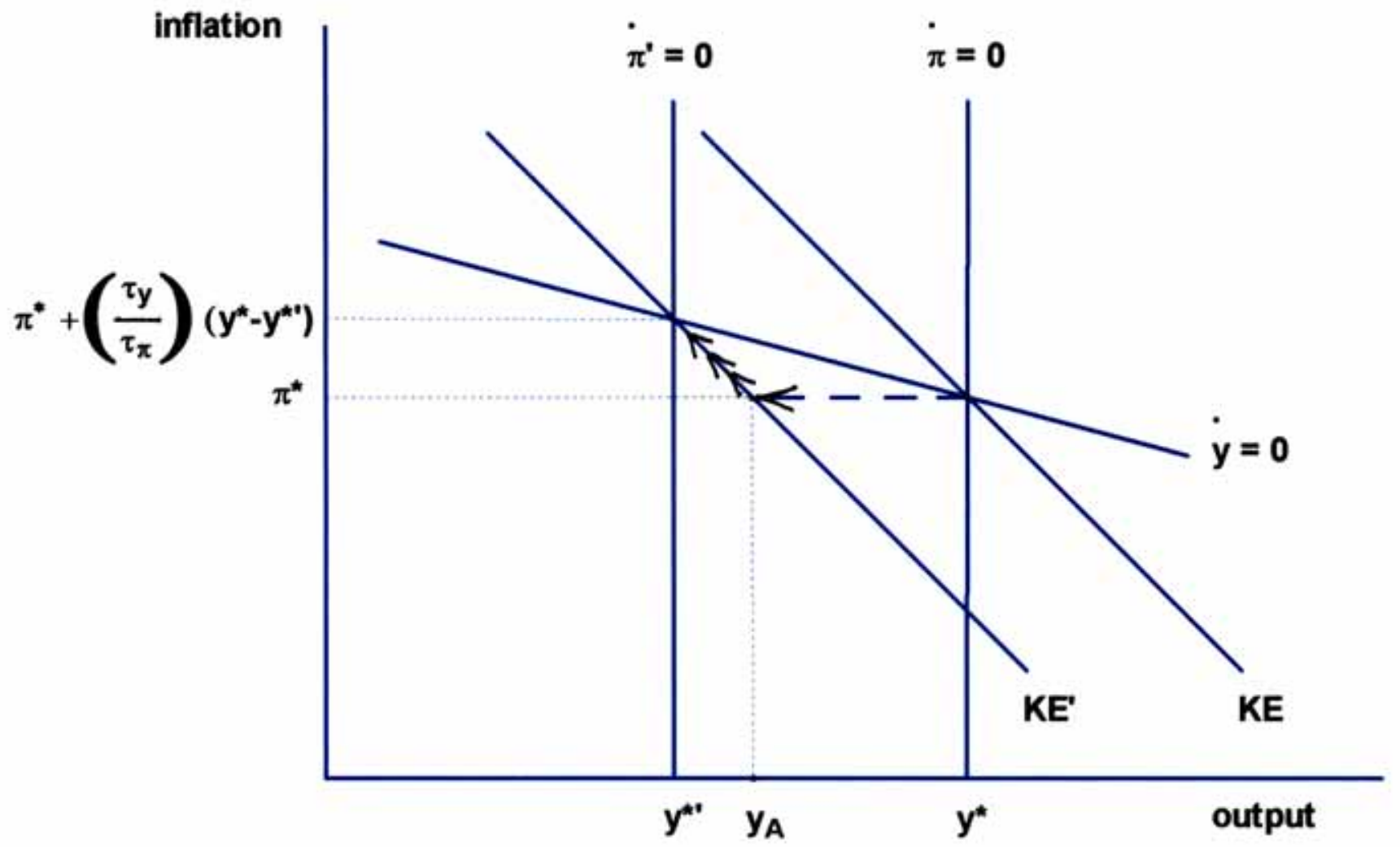

FIGURE 6. An unrecognized fall in potential output leads to stagflation, much as before. 